\title{
Research on university students' entrepreneurial intention and entrepreneurship education
}

\author{
Lina Liu \\ College of Computer Science, Neijiang Normal University; Neijiang, Sichuan 641112
}

18783270258@163.com

Keywords: Entrepreneurship education, Entrepreneurial intention of college students, Factor analysis

Abstract: Under the guidance of the spirit of the first session of the twelfth plenary meeting of the State Council, the mode of "popular entrepreneurship and innovation" has been greatly promoted, so that more young people could realize value of life, to better meet the needs of steady growth of Chinese economy to human resources in the transition period.

\section{Introduction}

Entrepreneurship education of college students, in fact, is to help students with entrepreneurial characteristics to improve their mental state of self-employed and improve the comprehensive quality of college students through the entrepreneurship education.

\section{Theoretical assumptions and model construction}

\subsection{College Students' entrepreneurial intention}

Definition of "entrepreneurship of college students" in the study: the process of students with the school status in full-time ordinary higher learning institutions (from the academic point of view, including junior college students, graduates, graduate students, and doctoral students) engaged in business activities or partnership business establishment.

\subsection{Entrepreneurship education constructed in multi dimension}

This study suggests that the research of entrepreneurial education on entrepreneurial intention of university students should take "entrepreneurship education" as a multi-dimensional construction, and conduct research from the three dimensions of the entrepreneurship psychological quality, entrepreneurial awareness and entrepreneurial knowledge, and lay emphasis on cultivating the entrepreneurial spirit of college students.

\subsection{Design of theoretical model}

2.3.1 Model construction: Based on the theory of planned behavior and entrepreneur theory and according to the previous logical reasoning, this study provides a theoretical model of the relationship between entrepreneurship education and college students' entrepreneurial intention.

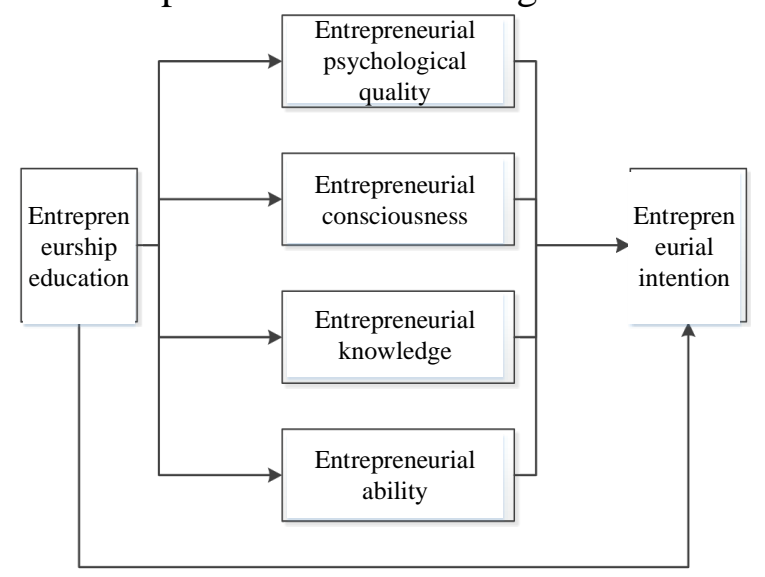

Figure 2.1 Theoretical model in the study 
2.3.2 The correspondence between model design and theoretical assumptions: This study focuses on the problems to be solved and takes the theory of planned behavior and entrepreneur theory as foundation, and constructs the theoretical framework of the influence of entrepreneurship education on entrepreneurial intention of college students.

\section{Empirical analysis}

This paper mainly studies the influence relationship of university students' entrepreneurial intention and entrepreneurship education. The author focuses on studying related issues in the individual level of students, and then deduces the results to the group level of college students.

\subsection{Questionnaire design and Implementation}

This survey sample covers many colleges and universities throughout the countrythe. In big education province such as the province of Shaanxi, the sample size accounts for $24.32 \%$, Beijing accounts for $20.54 \%$, Hubei accounts for $17.57 \%$. Sample collection in this study uses simple random sampling method, and a total of 385 questionnaires are recovered. Among them, number of effective questionnaires are 370 , and the effective recovery rate is $96.1 \%$.

\subsection{Descriptive statistical analysis of sample data}

In this part, the main control variables of this study are analyzed in the form of "sample proportion diagram" to directly determine the proportion of each variable. 370 valid questionnaires are statistically analyzed, and the descriptive statistics information of the sample is obtained. In the sample, men account for $51.62 \%$, women account for $48.38 \%$, and sex ratio is moderate, in accordance with the requirements of this study. In school type, "985" colleges and universities account for $14.05 \%$, "211" colleges and universities account for $33.51 \%$, other categories account for $52.43 \%$, and the results are in line with the forecast of this study.

\subsection{Regression analysis}

In order to prove hypothesis Hl、HZ、H3、H4、HS、H6、H7、HS and Hg, X1, X2, X3 and X4 are used to present respectively entrepreneurship psychological quality, entrepreneurial awareness, entrepreneurial knowledge and entrepreneurial ability, and $\mathrm{Y}$ presents college students' entrepreneurial intention to establish the multiple linear regression models in this study, as follows:

$$
Y=a+b X_{2}+c X_{2}+d X_{3}+e X_{4}+\varepsilon
$$

Wherein : $\quad Y=-0.286+0.164 X_{1}+0.216 X_{2}+0.45 X_{3}+0.267 X_{4}$ is referred to as random error. To estimate the values of unknown parameters a, b, c, $d$ and e in multiple linear regression equations is the core tasks of regression analysis in this research model.

Regression model analysis

In this part the linear regression analysis method is used to conduct regression analysis of questionnaire data. Here, the variable to be explained is college students' entrepreneurial intention $(\mathrm{Y})$, and the explanatory variables are the entrepreneurship psychological quality (X1), entrepreneurial awareness (X2), entrepreneurial knowledge (X3) and entrepreneurial ability (X4). Conduct forced entry analysis of explanatory variables on the study variables, and do the multicollinearity diagnosis. The analysis results are shown in Table 3.1 (A):

Tab 3.1 (A) The results of multiple linear regression analysis of the dimensions of entrepreneurship education (1)

\begin{tabular}{|c|c|c|c|c|}
\hline Model & $\mathrm{R}$ & R Square & Adjust R Square & $\begin{array}{c}\text { Variance of standard } \\
\text { estimate }\end{array}$ \\
\hline 1 & 0.871 & 0.758 & 0.756 & 0.52764 \\
\hline
\end{tabular}

Summary results of the model in table 3.1 (A) show that $\mathrm{R}$ square measures the linear correlation degree between the whole $\mathrm{X}$ and $\mathrm{Y}$, but also measures the correlation degree between the sample data and fitting data, and in multiple linear regression analysis, the adjusted $\mathrm{R}$ square could more accurately reflect the correlation goodness of the regression equation. Because the value of the adjusted $\mathrm{R}$ square is 0.756 , close to 1 , it could be considered that the regression equation model established in this study has high correlation goodness. 
Tab 3.1 (B) The results of multiple linear regression analysis of the dimensions of entrepreneurship education (2)

\begin{tabular}{|c|c|c|c|c|c|}
\hline Model & & Sum of squares & df & Mean square & F \\
\hline 1 & Regression & 318.903 & 4 & 79.726 & 286.363 \\
\hline & Residual & 101.619 & 365 & 0.278 & \\
\hline & In total & 420.521 & 369 & & \\
\hline
\end{tabular}

According to the regression results of table 3.1(B), it is shown that the total deviation square of variable to be explained, entrepreneurial intention of university students is 420.521 . Regression sum of squares and mean square are respectively 318.903 and 79.726, and the residual sum of squares and mean square are respectively 101.619 and 0.278 . Observed value of the $F$ test statistic is 286.363, and the value of the corresponding probability $\mathrm{P}$ is approximately 0 . Table 3.1 (B) could also be used to test the significance of the regression equation of this study, and the test uses the $\mathrm{F}$ statistics, and we could get that the regression equation established in this study is significant.

Tab 3.1 (C) The results of multiple linear regression analysis of the dimensions of entrepreneurship education (3)

\begin{tabular}{|c|c|c|c|c|c|c|c|c|}
\hline Model & & $\mathrm{B}$ & $\begin{array}{c}\text { Standard } \\
\text { error }\end{array}$ & Trial & $\mathrm{t}$ & Sig & Tolerance & $\mathrm{VIF}$ \\
\hline 1 & -0.286 & 0.11 & & -2.609 & 0.009 & & \\
\hline & $\begin{array}{c}\text { Entrepreneurship } \\
\text { psychological } \\
\text { quality }\end{array}$ & 0.164 & 0.032 & 0.181 & 5.178 & 0 & 0.539 & 1.854 \\
\hline & $\begin{array}{c}\text { Entrepreneurial } \\
\text { awareness }\end{array}$ & 0.216 & 0.049 & 0.178 & 4.415 & 0 & 0.406 & 2.46 \\
\hline & $\begin{array}{c}\text { Entrepreneurial } \\
\text { knowledge }\end{array}$ & 0.450 & 0.044 & 0.428 & 10.172 & 0 & 0.374 & 2.676 \\
\hline $\begin{array}{c}\text { Entrepreneurial } \\
\text { ability }\end{array}$ & 0.267 & 0.046 & 0.216 & 5.783 & 0 & 0.475 & 2.106 \\
\hline
\end{tabular}

It could be seen from the table that significant test of this model is conducted by sampling distribution of partial regression coefficient estimation value, so test statistics in accordance with the theory of planned behavior and entrepreneur theory are constructed, according to the regression coefficient test table, the regression equation could be written in this study.

$$
Y=-0.286+0.164 X_{1}+0.216 X_{2}+0.45 X_{3}+0.267 X_{4}
$$

\section{Conclusion}

Based on the theory of planned behavior and entrepreneur theory, the theoretical hypothesis in the paper are tested by using the methods of literature derivation and empirical research, and the effect path of entrepreneurship education on entrepreneurial intention of university students is explored deeply under the environment of popular innovation and entrepreneurship.

\section{References}

[1] Oosterbeek H, Van Praag M, Ijsselstein A. The impact of entrepreneurship education on entrepreneurship skills and motivation[J]. European economic review, 2010, 54(3): 442-454.

[2] Schwarz E J, Wdowiak M A, Almer-Jarz D A, et al. The effects of attitudes and perceived environment conditions on students' entrepreneurial intent: An Austrian perspective[J]. Education+ Training, 2009, 51(4): 272-291.

[3] Lee S M, Chang D, Lim S B. Impact of entrepreneurship education: A comparative study of the US and Korea[J]. The International Entrepreneurship and Management Journal, 2005, 1(1): 27-43. 
[4] Byabashaija W, Katono I. The impact of college entrepreneurial education on entrepreneurial attitudes and intention to start a business in Uganda[J]. Journal of Developmental Entrepreneurship, 2011, 16(01): 127-144.

[5] Oosterbeek H, Van Praag M, IJsselstein A. The impact of entrepreneurship education on entrepreneurship competencies and intentions: An evaluation of the Junior Achievement Student Mini-Company Program[J]. Available at SSRN 1118251, 2008. 